\title{
Genotypic and Phenotypic Detection of Macrolide and Lincosamide Resistance in Streptococcus uberis
}

\author{
E. Schmitt-van de Leemput* and R. N. Zadoks† \\ ${ }^{*}$ Clinique Vétérinaire de Villaines La Juhel, Villaines La Juhel, France \\ †Quality Milk Production Services, Cornell University, Ithaca, NY 14850-1263
}

\begin{abstract}
Streptococcus uberis isolates $(\mathrm{n}=55)$ were obtained from milk samples of cases of mild clinical mastitis in 55 dairy cows from 35 herds serviced by one veterinary practice in Mayenne, France. Isolates were tested for macrolide and lincosamide resistance by using phenotypic and genotypic methods. Erythromycin resistance was detected in 12 of the $55(22 \%)$ isolates based on agar disc diffusion testing and MIC measurements, and was encoded by erm $\mathrm{B}$. This gene also conferred phenotypic resistance to pirlimycin based on MIC measurements, but the D-test was needed for detection of the resistance phenotype in the agar disc diffusion test. Isolates with erm B were also highly resistant to the macrolide antibiotic spiramycin. Seventeen of the 55 isolates $(31 \%)$ were classified as resistant to spiramcyin only and as having intermediate susceptibility to spiramycin based on agar disc diffusion testing and MIC measurements, respectively. The genetic mechanism behind this phenotype and its clinical relevance are unknown. The efflux pump gene mefA was not detected in any of the 55 isolates in this study. Pirlimycin resistance without macrolide resistance was encoded by the lincosamide resistance gene $\operatorname{lin} \mathrm{B}$ in 4 isolates. Based on current guidelines, some lin B-positive isolates would be classified as susceptible by using phenotypic tests, and alternative values for the interpretation of the agar disc diffusion test are suggested. We conclude that the agar disc diffusion test is a useful indicator for macrolide and lincosamide resistance of Strep. uberis in veterinary practice, provided that the $\mathrm{D}$-test is used for detection of pirlimycin resistance.
\end{abstract}

Key words: Streptococcus uberis, macrolide, lincosamide, antimicrobial resistance

\section{INTRODUCTION}

Streptococcus uberis is a major cause of mastitis in dairy cattle around the world (Erskine et al., 2002;

Received February 8, 2007.

Accepted July 7, 2007.

${ }^{1}$ Corresponding author: rz26@cornell.edu
Guérin-Faublée et al., 2002; McDougall et al., 2007). Several antimicrobial products are licensed and used for treatment of clinical and subclinical Strep. uberis mastitis during lactation (Deluyker et al., 2005; Milne et al., 2005; McDougall et al., 2007). The choice of antimicrobial products for mastitis treatment depends on the availability and regulation of veterinary drugs and differs across states and countries (Grave et al., 1999; Zwald et al., 2004; Sawant et al., 2005; Tenhagen et al., 2006). Cephalosporins are the most commonly used compounds in Brandenburg, Germany (Tenhagen et al., 2006), Pennsylvania (Sawant et al., 2005), and Washington State (Raymond et al., 2006), whereas penicillin and ampicillin are the most commonly used drugs for treatment of mastitis in several other states in the United States (Zwald et al., 2004). In the practice area of one of the authors in France, spiramycin is the most frequently used compound. Spiramycin has also been used for mastitis treatment in Norway and Sweden (Grave et al., 1999). Together with erythromycin, which is used in the United States (Zwald et al., 2004), and tylosin, which is used for treatment of streptococcal mastitis in New Zealand (McDougall et al., 2007), spiramycin belongs to the class of macrolide antimicrobials. A closely related class of antimicrobials, the lincosamides, includes pirlimycin, which is used as intramammary treatment in Europe (Deluyker et al., 2005) and the United States (Raymond et al., 2006).

Resistance to macrolides and lincosamides is widespread among streptococci, and horizontal transfer of resistance genes is possible (Loch et al., 2005; Martel et al., 2005). Data on macrolide and lincosamide resistance of Strep. uberis suggest that the prevalence of resistance may have increased over the past decades (Loch et al., 2005). Mechanisms that encode resistance to macrolide-, lincosamide-, and Streptogramin B (MLS)-type antimicrobials include ribosomal methylases, which are mostly encoded by ermB or erm TR in streptococci; efflux pumps, such as those encoded by mefA; and ribosomal mutations (Roberts, 2002). Antimicrobial resistance in mastitis pathogens can be detected by phenotypic methods, such as agar disc diffusion or microbroth dilution tests (CLSI, 2004), and by 
genotypic methods, specifically through detection of resistance genes. In veterinary practice, susceptibility testing by means of agar disc diffusion assays is used to decide whether MLS compounds might be appropriate for treatment of mastitis in specific animals or herds. One of many limitations of phenotypic resistance tests in vitro is that test results are measured on a continuous or logarithmic scale, such as the diameter of an inhibition zone or the concentration of an antimicrobial compound that inhibits bacterial growth. These continuous measurements need to be interpreted in terms of a categorical variable, that is, susceptible, intermediate, or resistant. The choice of cutoff values is ideally supported by clinical data, but may be ambiguous. By contrast, the presence or absence of a resistance gene is a categorical variable in and of itself, although the phenotypic manifestation of resistance depends on gene expression (e.g., Levin et al., 2005).

The goal of this study was to examine the macrolide and lincosamide resistance of Strep. uberis isolates from cases of mild clinical mastitis by using phenotypic and genotypic methods, and to compare the classification of isolates as susceptible or resistant by both methods. Ultimately, this may contribute to a better understanding of interpretation criteria for phenotypic methods that are used in veterinary practice.

\section{MATERIALS AND METHODS}

\section{Bacterial Isolates}

Streptococcus uberis isolates $(\mathrm{n}=55)$ were obtained from milk samples of cases of mild clinical mastitis diagnosed by dairy farmers in 55 dairy cows from 35 herds serviced by one veterinary practice in La Mayenne, in the western part of France. The area covered by this practice is approximately 40 by $40 \mathrm{~km}$. Milk samples were collected aseptically by the attending veterinarian between July and December 2004, following National Mastitis Council recommended procedures (National Mastitis Council, 1999). Per herd, between 1 and 7 cows were sampled, with a median of 1 cow and an average of 1.6 cows per herd. Per sample, $10 \mu \mathrm{L}$ was plated onto trypticase soy agar containing $5 \%$ sheep blood and $0.1 \%$ esculin (bioMérieux, Marcy l'Etoile, France) by using calibrated loops. Plates were incubated aerobically for 24 to $48 \mathrm{~h}$ at $37^{\circ} \mathrm{C}$. Preliminary identification of Strep. uberis was based on colony morphology, esculin splitting, and catalase testing (National Mastitis Council, 1999). Bacterial lysates of pure subcultures of suspected Strep. uberis isolates were prepared (Furrer et al., 1991) and species identity was confirmed by PCR (Hassan et al., 2001). When multiple isolates from a herd were available, strain typing was performed by means of random-amplified polymorphic
DNA (RAPD) PCR by using primer ERIC-1R (5'-ATGTAAGCTCCTGGGGATTCAC-3') and initial denaturation for $4 \mathrm{~min}$ at $94^{\circ} \mathrm{C}$, followed by 44 cycles of $30 \mathrm{~s}$ at $94^{\circ} \mathrm{C}, 60 \mathrm{~s}$ of annealing at $35^{\circ} \mathrm{C}$ and $90 \mathrm{~s}$ of elongation at $72^{\circ} \mathrm{C}$, and a final elongation step of $7 \mathrm{~min}$ at $72^{\circ} \mathrm{C}$. Amplified products and molecular size markers (BenchTop 100-bp DNA ladder, Promega, Madison, WI) were separated by electrophoresis in 1.5\% agarose gel in $0.5 \%$ Tris-boric acid-EDTA buffer at $95 \mathrm{~V}$ for $90 \mathrm{~min}$. Gels were stained with ethidium bromide, and DNA was made visible by UV transillumination by using the Molecular Imager Gel Doc XR System (Bio-Rad, Hercules, CA) and Quantity One software (version 4.4.1, BioRad). Isolates with the same number and size of DNA fragments were considered to belong to the same RAPD type, irrespective of the band intensity of fragments.

\section{Detection of Resistance Phenotype}

Phenotypic susceptibility testing for the macrolides erythromycin and spiramycin and the lincosamide pirlimycin was performed for all 55 isolates by agar disc diffusion testing on Mueller-Hinton agar with 5\% sheep blood (bioMérieux). Plates were streaked with a cotton swab drenched in a suspension of Strep. uberis at a concentration of approximately $10^{7} \mathrm{cfu} / \mathrm{mL}$, and discs impregnated with erythromycin ( $15 \mu \mathrm{g}$, bioMérieux), spiramycin (100 $\mu \mathrm{g}$, bioMérieux), or pirlimycin ( $2 \mu \mathrm{g}$, Pfizer, Paris, France) were positioned on the agar. Plates were incubated aerobically at $37^{\circ} \mathrm{C}$ for $24 \mathrm{~h}$, and the diameter of the growth inhibition zone around each disc was measured. Isolates were considered susceptible for erythromycin, spiramycin, and pirlimycin if inhibition zones were $\geq 21, \geq 24$, and $\geq 13 \mathrm{~mm}$, respectively, and resistant if inhibition zones were $\leq 15, \leq 18$, and $\leq 12 \mathrm{~mm}$, respectively (Bryskier, 1999; CLSI, 2004). For erythromycin and spiramcyin, isolates with inhibition zones between the values listed were categorized as intermediate. For isolates that seemed erythromycin resistant and pirlimycin susceptible, the D-test (Levin et al., 2005) was performed (pirlimycin and erythromycin discs were placed at an edge-to-edge distance of 15 to $20 \mathrm{~mm}$, and flattening of the inhibition zone around the pirlimycin disc on the side of the erythromycin disc, resulting in an inhibition zone shaped like the letter $\mathrm{D}$, was assessed). The principle behind the D-test is that erythromycin induces the expression of erm genes, which may be present but are not constitutively expressed in all isolates that carry the gene. Once the gene is expressed, the gene product, a ribosomal methylase, confers resistance to macrolide as well as lincosamide antibiotics (Levin et al., 2005).

For a subset of isolates $(\mathrm{n}=30)$, MIC values were determined. This subset was selected to include 3 popu- 
lations of isolates with approximately 10 isolates for each group, that is, 1) all isolates that were resistant to spiramycin with an inhibition zone of $0 \mathrm{~mm}(\mathrm{n}=$ $12) ; 2$ ) isolates that were resistant to spiramycin with inhibition zones of 12 to $16 \mathrm{~mm}(\mathrm{n}=10)$; and 3$)$ isolates that were susceptibile to spiramycin with inhibition zones of $\geq 24 \mathrm{~mm}(\mathrm{n}=8)$. Resistance to spiramycin was determined with the agar plate dilution method by using 13 dilutions of spiramcyin (Sigma-Aldrich, Lyon, France) in Mueller-Hinton agar with 5\% sheep blood (bioMérieux) and $10^{4}$ cfu of Strep. uberis per plate. Resistance to erythromycin and pirlimycin was determined with the Trek Sensititre Mastitis Panel CMV1AMAF (Trek Diagnostic Systems, Cleveland, OH). Testing for spiramycin was performed separately because the compound is not available in the United States. Isolates were considered susceptible for erythromycin, spiramycin, and pirlimycin if MIC were, respectively, $\leq 0.25, \leq 1$, and $\leq 2 \mu \mathrm{g} / \mathrm{mL}$; resistant if MIC were, respectively, $\geq 1,>4$, and $\geq 4 \mu \mathrm{g} / \mathrm{mL}$; and intermediate for erythrymoycin and spiramycin if MIC values were between the values listed (Bryskier, 1999; CLSI, 2004). Zone diameters and breakpoints as listed here are specific for streptococci other than Streptococcus pneumoniae. Only the values for pirlimycin are specific for bovine mastitis (CLSI, 2004). Agreement between results from agar disc diffusion and MIC testing, categorized as susceptible, intermediate, and resistant, or as susceptible vs. nonsusceptible, was quantified by using the kappa statistic (WinEpiscope 2.0, available through http:// www.qve.wur.nl/UK/education/; accessed April 4, 2007).

\section{Detection of Resistance Genes}

Detection of resistance genes was performed as described previously (Loch et al., 2005). All isolates were tested for the presence of erm $\mathrm{B}$ by using primers $5^{\prime}$ GAA AAG GTA CTC AAC CAA ATA-3' and 5'-AGT AAC GGT ACT TAA ATT GTT TAC-3' (Sutcliffe et al., 1996), and for the presence of mefA by using primers $5^{\prime}$-CTA TGA CAG CCT CAA TGC G-3' and 5'-ACC GAT TCT ATC AGC AAA G-3' (Wondrack et al., 1996). Isolates that showed phenotypic resistance to lincosamide, but not macrolide, antimicrobials were tested for the presence of $l i n \mathrm{~B}$ by using primers 5 '-CCT ACC TAT TGT TTG TGG AA- $3^{\prime}$ and $5^{\prime}$-ATA ACG TTA CTC TCC TAT TC-3' (Bozdogan et al., 1999). Polymerase chain reaction amplicons were purified by using the PureLink PCR Purification Kit (Invitrogen Corporation, Carlsbad, CA). Sequencing of purified PCR products was performed in 2 directions by using the PCR primers and Big Dye Terminator chemistry (Applied BioSystems, Foster City, CA) on an ABI Prism 3700 DNA analyzer

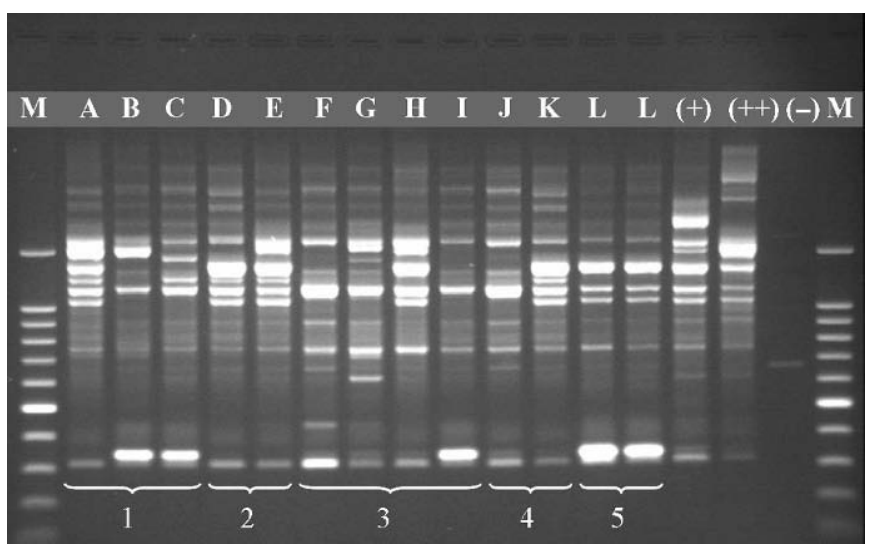

Figure 1. Strain typing results based on random-amplified polymorphic DNA (RAPD) PCR for herds for which 2 to 4 Streptococcus uberis isolates were included. $\mathrm{M}=$ molecular size marker; $(+)$ and $(++)=$ positive controls (Strep. uberis ATCC 27958 and ATCC 700407, respectively); $(-)=$ negative control; numbers indicate herds; letters $\mathrm{A}$ through L indicate RAPD patterns. Both isolates from herd 5 showed RAPD pattern L, but isolates differed in their resistance profile.

(Applied Biosystems). Sequence data were proofread in SeqMan (version 5.08, Lasergene, DNAStar Inc., Madison, WI), and compared with publicly available sequence data by using nucleotide-nucleotide BLAST (Altschul et al., 1997).

\section{RESULTS}

\section{Phenotypic Resistance}

For 28 herds, only one isolate was included in the study. When multiple isolates originated from the same herd, isolates differed in the RAPD banding pattern, resistance profile, or both (Figure 1), with the exception of 3 isolates from 1 herd, which shared the same RAPD pattern and highly similar resistance profiles. Results of susceptibility testing with the agar disc diffusion method are summarized in Figure 2. For erythromycin susceptibility, a dichotomous distribution was observed; that is, isolates were either fully resistant (Figure 2, isolates 1 through 12) or susceptible, with an inhibition zone of $30 \mathrm{~mm}$ or more (Figure 2, isolates 13 through 55). Erythromycin-resistant isolates were also resistant to spiramycin. Erythromycin-susceptible isolates could be divided into 3 subpopulations based on spiramycin susceptibility, with inhibition zones of 12 to $16 \mathrm{~mm}(\mathrm{n}=17$; Figure 2, isolates 13 through 29; resistant), 20 to $22 \mathrm{~mm}$ ( $\mathrm{n}=6$; Figure 2, isolates 30 through 35 ; intermediate), and $24 \mathrm{~mm}$ or greater ( $\mathrm{n}=$ 20 ; Figure 2, isolates 36 through 55; susceptible), respectively. Inhibition zones around pirlimycin discs were highly variable for erythromycin-resistant iso- 

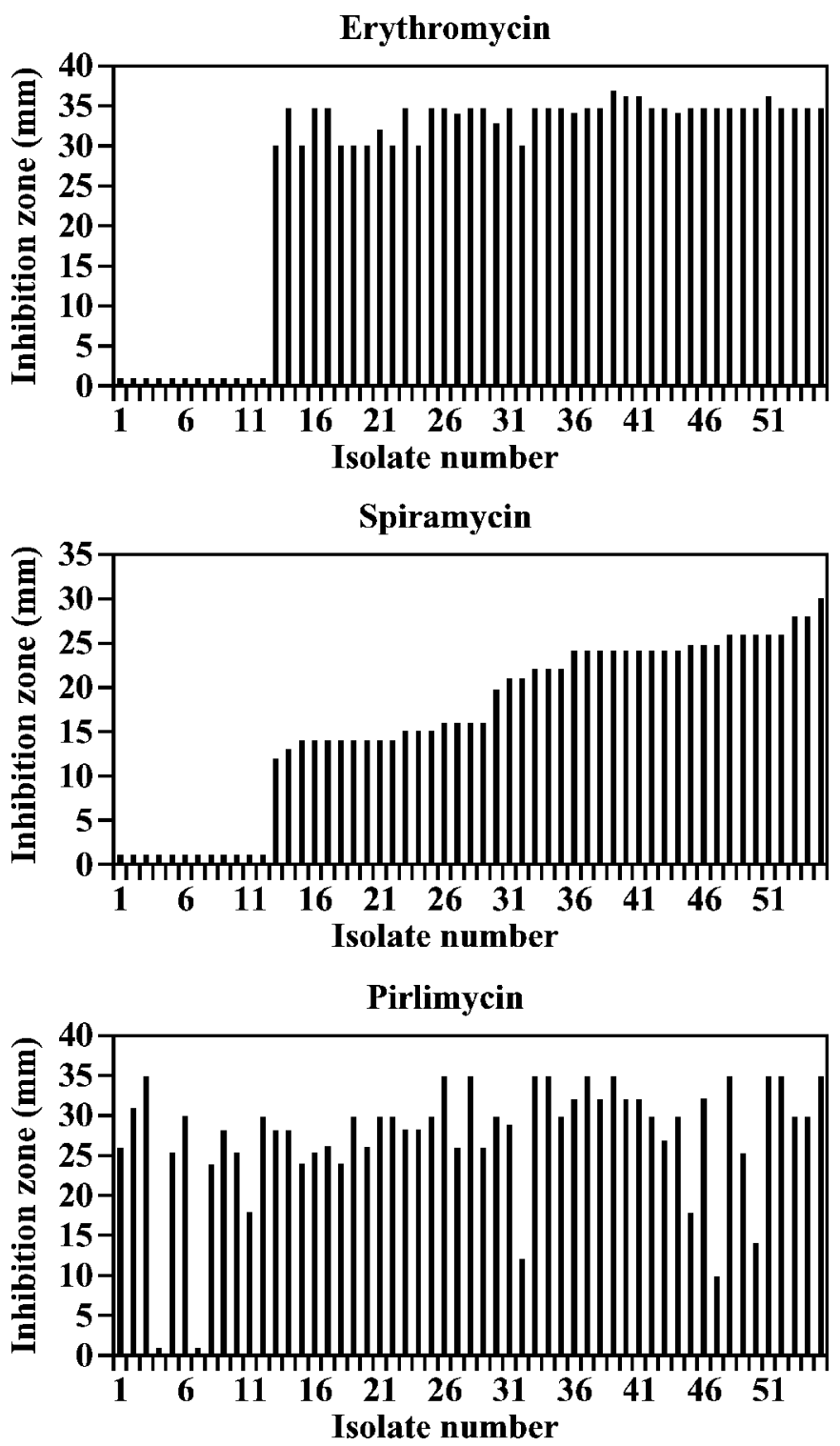

Figure 2. Inhibition zone (in $\mathrm{mm}$ ) for 55 Streptococcus uberis isolates around erythromycin- $(15 \mu \mathrm{g})$, spiramycin- $(100 \mu \mathrm{g})$, and pirlimycin- $(2 \mu \mathrm{g})$ impregnated discs on Mueller-Hinton agar with 5\% sheep blood. All panels show isolates in the same order. Disc diameter was $6 \mathrm{~mm}$. Results for isolates that grew up to the discs are shown as a 0 -mm inhibition zone.

lates, ranging from 0 to $35 \mathrm{~mm}$ (Figure 2, isolates 1 through 12), and zone diameters were not reproducible upon repeated testing. In many cases, growth of isolated colonies was observed within the inhibition zone, and prolonged incubation of plates resulted in additional growth in the area of initial inhibition. When the D-test was used, all erythromycin-resistant isolates showed resistance to pirlimycin (Figure 3). Erythromycin-susceptible isolates were divided into 2 subpopulations

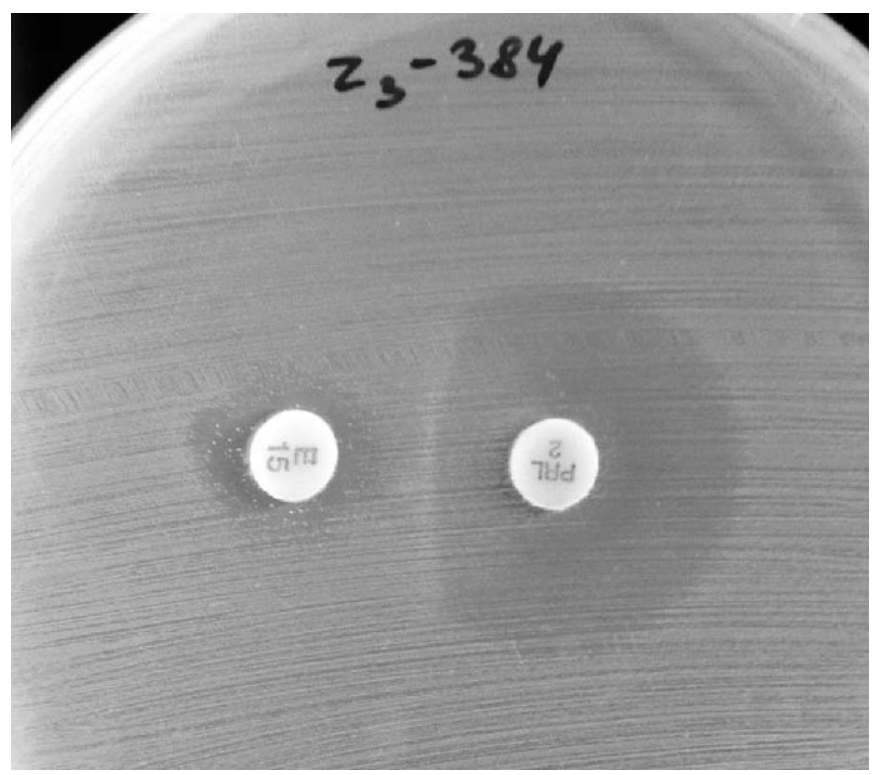

Figure 3. Example of the D-test, showing an inhibition zone that has the shape of the letter $\mathrm{D}$ around the pirlimycin disc (PRL) when placed at 15 to $20 \mathrm{~mm}$ from an erythromycin disc (E) in the agar disc diffusion assay.

based on pirlimycin susceptibility, with inhibition zones of 10 to $18 \mathrm{~mm}$ (isolates 32, 45, 47, and 50 in Figure 2; resistant or susceptible) or 24 to $35 \mathrm{~mm}$ (susceptible), respectively.

For erythromycin, full agreement (kappa $=1.0)$ between agar disc diffusion testing and MIC was observed for all resistant and susceptible isolates that were tested with both methods ( $\mathrm{n}=12$ and $\mathrm{n}=18$, respectively; Table 1). For spiramycin, partial agreement (kappa $=0.51)$ between phenotypic methods was observed. All isolates with inhibition zones of 12 to 16 $\mathrm{mm}$ had MIC of $4 \mu \mathrm{g} / \mathrm{mL}$ for spiramycin ( $\mathrm{n}=10$; Table 1). According to current guidelines, these isolates should be classified as resistant based on inhibition zone, and as intermediate based on MIC (Bryskier, 1999). The remaining isolates $(\mathrm{n}=8)$ had inhibition zones of $24 \mathrm{~mm}$ or greater and MIC of $\leq 4 \mu \mathrm{g} / \mathrm{mL}$, and would be classified as susceptible based on both phenotypic methods (Table 1). When intermediate and resistant isolates were grouped together as nonsusceptible isolates, agreement between the 2 phenotypic methods was high (kappa $=0.91$ ). For pirlimycin, as for spiramycin, partial agreement between phenotypic methods was observed (kappa $=0.87)$. All isolates $(n=15)$ with inhibition zones of $24 \mathrm{~mm}$ or greater had MIC of $\leq 0.25 \mu \mathrm{g} / \mathrm{mL}$ and were classified as susceptible based on both methods. All D-test-positive isolates $(\mathrm{n}=12)$ had MIC of $>4 \mu \mathrm{g} / \mathrm{mL}$ and were considered resistant based on both methods (Table 1). Four additional iso- 
Table 1. Phenotypic and genotypic resistance profiles for 30 isolates of Streptococcus uberis from bovine clinical mastitis

\begin{tabular}{|c|c|c|c|c|c|c|c|c|c|c|c|c|c|}
\hline \multirow[b]{3}{*}{ Number } & \multicolumn{4}{|c|}{ Erythromycin } & \multicolumn{4}{|c|}{ Spiramycin } & \multicolumn{4}{|c|}{ Pirlimycin } & \multirow[b]{3}{*}{ Gene } \\
\hline & \multicolumn{2}{|c|}{$\mathrm{ADD}^{1}$} & \multicolumn{2}{|c|}{$\mathrm{MIC}^{2}$} & \multicolumn{2}{|c|}{$\mathrm{ADD}$} & \multicolumn{2}{|c|}{ MIC } & \multicolumn{2}{|c|}{$\mathrm{ADD}$} & \multicolumn{2}{|c|}{ MIC } & \\
\hline & $\mathrm{mm}$ & SIR & $\mu \mathrm{g} / \mathrm{mL}$ & SIR & $\mathrm{mm}$ & SIR & $\mu \mathrm{g} / \mathrm{mL}$ & SIR & $\mathrm{mm}$ & SIR & $\mu \mathrm{g} / \mathrm{mL}$ & SIR & \\
\hline 2 & 0 & $\mathrm{R}$ & $>4$ & $\mathrm{R}$ & 0 & $\mathrm{R}$ & 8 & $\mathrm{R}$ & $\mathrm{D}^{3}$ & $\mathrm{R}$ & $>4$ & $\mathrm{R}$ & erm $\mathrm{B}$ \\
\hline 2 & 0 & $\mathrm{R}$ & $>4$ & $\mathrm{R}$ & 0 & $\mathrm{R}$ & 64 & $\mathrm{R}$ & $\mathrm{D}$ & $\mathrm{R}$ & $>4$ & $\mathrm{R}$ & erm B \\
\hline 3 & 0 & $\mathrm{R}$ & $>4$ & $\mathrm{R}$ & 0 & $\mathrm{R}$ & 128 & $\mathrm{R}$ & D & $\mathrm{R}$ & $>4$ & $\mathrm{R}$ & erm $\mathrm{B}$ \\
\hline 5 & 0 & $\mathrm{R}$ & $>4$ & $\mathrm{R}$ & 0 & $\mathrm{R}$ & $>256$ & $\mathrm{R}$ & $\mathrm{D}$ & $\mathrm{R}$ & $>4$ & $\mathrm{R}$ & erm B \\
\hline 10 & $\geq 30$ & $\mathrm{~S}$ & $\leq 0.25$ & $\mathrm{~S}$ & $12-16$ & $\mathrm{R}$ & 4 & I & $\geq 24$ & $\mathrm{~S}$ & $\leq 0.5$ & $\mathrm{~S}$ & \\
\hline 1 & $\geq 30$ & $\mathrm{~S}$ & $\leq 0.25$ & $\mathrm{~S}$ & $\geq 24$ & $\mathrm{~S}$ & 4 & I & $\geq 24$ & $\mathrm{~S}$ & $\leq 0.5$ & $\mathrm{~S}$ & \\
\hline 3 & $\geq 30$ & $\mathrm{~S}$ & $\leq 0.25$ & $\mathrm{~S}$ & $\geq 24$ & $\mathrm{~S}$ & $\leq 0.5$ & $\mathrm{~S}$ & $\geq 24$ & $\mathrm{~S}$ & $\leq 0.5$ & $\mathrm{~S}$ & \\
\hline 2 & $\geq 30$ & $\mathrm{~S}$ & $\leq 0.25$ & $\mathrm{~S}$ & $\geq 24$ & $\mathrm{~S}$ & $\leq 0.5$ & $\mathrm{~S}$ & $14-18$ & $\mathrm{~S}$ & $>4$ & $\mathrm{R}$ & $\operatorname{lin} \mathrm{B}^{4}$ \\
\hline 1 & $\geq 30$ & $\mathrm{~S}$ & $\leq 0.25$ & $\mathrm{~S}$ & $\geq 24$ & $\mathrm{~S}$ & 2 & $\mathrm{~S}$ & 10 & $\mathrm{R}$ & 4 & $\mathrm{R}$ & $\operatorname{lin} \mathrm{B}$ \\
\hline 1 & $\geq 30$ & $\mathrm{~S}$ & $\leq 0.25$ & $\mathrm{~S}$ & $\geq 24$ & $\mathrm{~S}$ & 1 & $\mathrm{~S}$ & $\geq 24$ & $\mathrm{~S}$ & $\leq 0.5$ & $\mathrm{~S}$ & \\
\hline
\end{tabular}

${ }^{1} \mathrm{ADD}=$ agar disc diffusion test $; \mathrm{mm}$ = inhibition zone in $\mathrm{mm}$; SIR = classification of isolate as susceptible $(\mathrm{S})$, intermediate (I), or resistant (R).

${ }^{2} \mathrm{MIC}=$ minimum inhibitory concentration in $\mu \mathrm{g} / \mathrm{mL}$.

${ }^{3} \mathrm{D}=$ resistance visible in $\mathrm{D}$-test (i.e., as $\mathrm{D}$-shaped inhibition zone around the pirlimycin disc when placed at 15 to $20 \mathrm{~mm}$ from the erythromycin disc).

${ }^{4}$ Isolates originated from 2 herds. For 1 herd, 2 additional $\operatorname{lin} \mathrm{B}$-positive isolates were available, of which one is included in this table and one had an inhibition zone of $12 \mathrm{~mm}$ and MIC of $>4 \mu \mathrm{g} / \mathrm{mL}$. The $3 \operatorname{lin} \mathrm{B}$ positive isolates from this herd belonged to the same strain of Strep. uberis, based on random-amplified polymorphic DNA typing.

lates with MIC of $\geq 4 \mu \mathrm{g} / \mathrm{mL}$ had inhibition zones of 10 to $18 \mathrm{~mm}$, and did not show inducible resistance in the D-test. Based on current guidelines for interpretation of the agar disc diffusion assay, 2 isolates should be considered susceptible (inhibition zones of 14 and 18 $\mathrm{mm}$, respectively) and 2 isolates should be considered resistant (inhibition zones of 10 and $12 \mathrm{~mm}$, respectively). Only 3 of these 4 isolates are shown in Table 1 , because 1 isolate was not included in the set selected for MIC testing based on spiramycin susceptibility. In erythromycin and pirlimycin assays, the results obtained for quality control organisms (Staphylococcus aureus ATCC 29213 and the Enterococcus faecalis ATCC 29212) were within published ranges. Control organisms have not been specified for spiramycin testing.

\section{Resistance Genes}

All isolates were tested for the presence of the ribosomal methylase gene ermB. The gene was detected in 12 isolates, all of which were phenotypically resistant to erythromycin, spiramycin, and pirlimycin based on both phenotypic methods (Table 1). Isolates with erm $\mathrm{B}$ originated from 12 cows in 11 herds. Three erm B alleles were detected based on analysis of a 523-bp fragment of the coding sequence. One allele, detected in 7 isolates, was identical to the previously identified allele ermB3 (Loch et al., 2005; GenBank accession no. EF539836). In one herd, this allele was detected in 2 Strep. uberis strains (Figure 1, herd 1, strains A and B). Two other ermB alleles, identified 4 times (GenBank accession no. EF540937) and once (GenBank accession no. EF540938), respectively, had not previously been described for Strep. uberis. Of 55 isolates, none tested positive for mefA. Macrolide-susceptible isolates that showed phenotypic resistance to pirlimycin in one or both of the phenotypic assays were tested for the presence of the lincosamide resistance gene $\operatorname{lin} \mathrm{B}$. This gene was detected in all 4 isolates, belonging to 2 strains and originating from 2 herds. Three cows in one herd were infected with the same linB-positive strain of Strep. uberis based on RAPD typing. The sequence of the lin B amplicon was identical for the 4 isolates (GenBank accession no. EF539833) and showed 99\% homology with the linB gene of Enterococcus faecium (GenBank accession no. AJ238249 and AF110130).

\section{DISCUSSION}

In this study on isolates from France, as in a previous study on isolates from the southwestern United States (Loch et al., 2005), macrolide resistance in Strep. uberis from bovine mastitis was encoded by erm $\mathrm{B}$. The number of isolates, herds, and geographic areas of origin were limited for both studies, and results from these studies may not apply to Strep. uberis populations elsewhere. The erm $\mathrm{B}$ gene confers phenotypic resistance to macrolide-type (e.g., erythromycin and spiramycin) as well as lincosamide-type (e.g., pirlimycin) antimicrobials in 
vitro. The agar disc diffusion test, which is the most practical and affordable antimicrobial susceptibility test method in veterinary practice, clearly indicates resistance to macrolides in isolates carrying ermB. For detection of pirlimycin resistance, the $\mathrm{D}$-test or a brothbased method must be used. Otherwise, the erm $\mathrm{B}$ gene may not be expressed and resistance could go undetected. Our results seem to suggest that lack of expression of the erm $\mathrm{B}$ gene is specifically associated with the agar disc diffusion method and need not be indicative of lack of expression of this resistance gene in vivo. Macrolide-lincosamide disconcordant isolates (i.e., isolates that express macrolide but not lincosamide resistance in vitro) also occur in humans, and the D-test is used to detect inducible resistance to lincosamides (Levin et al., 2005). After lincosamide therapy of human patients infected with D-test-positive isolates, both treatment successes and treatment failures have been reported (Levin et al., 2005). The relevance of antimicrobial resistance in vitro as a predictor of treatment response in vivo is disputed (Constable and Morin, 2003; Hoe and Ruegg, 2005). Proponents of susceptibility testing claim that resistance testing is useful in veterinary practice to ensure that infected animals are not treated with compounds to which the infectious agent shows resistance in vitro (Barkema et al., 2006). In the authors' opinion, bacterial culture and antimicrobial susceptibility testing are helpful to develop a herd level profile and treatment protocol, to adjust treatment of nonresponsive cases, and to select treatment of chronic infections that may be subclinical or manifest with occasional clinical flare-ups. Studies of the response of Strep. uberis mastitis to treatment with MLS antibiotics have considered host factors that affect the chance of cure, but not pathogen factors (Deluyker et al., 2005; McDougall et al., 2007). In treatment trials of mastitis caused by another gram-positive pathogen, Staph. aureus, pathogen factors affected the chance of cure (Barkema et al., 2006). To improve our understanding of the usefulness of in vitro antimicrobial resistance testing, it would be of great value if future treatment trials included pathogen-level risk factors, specifically antimicrobial resistance.

Resistance to lincosamides, a group of antimicrobials that includes not only pirlimycin but also lincomycin and clindamycin, is commonly encoded by ribosomal methylase genes, which confer cross-resistance to other classes of MLS-type antimicrobials (Roberts, 2002). By contrast, genes conferring resistance to lincosamides through nucleotidylation (i.e., $\operatorname{lin} \mathrm{A}$ and $\operatorname{lin} \mathrm{B}$ ) encode resistance to lincosamides but not macrolides (Bozdogan et al., 1999). In the current study, 4 isolates were detected that were susceptible to erythromycin, but not to pirlimycin. In all 4 isolates, the lincosamide resis- tance gene lin $\mathrm{B}$ was detected. Three isolates originated from the same herd, and belonged to the same strain of Strep. uberis. Previously, the presence of $\operatorname{lin} \mathrm{B}$ was described in $E$. faecium but not $E$. faecalis, leading to the suggestion that the gene is specific for $E$. faecium (Bozdogan et al., 1999). As part of ongoing studies in our laboratory, the gene has also been detected in Strep. uberis isolates from New York State (GenBank accession no. EF539832). Isolates from New York that carried the lin $\mathrm{B}$ gene had phenotypic antimicrobial susceptibility profiles similar to those from France; that is, they were susceptible to erythromycin based on agar disc diffusion and MIC testing, and resistant to pirlimycin (inhibtion zone 10 to $12 \mathrm{~mm}, \mathrm{MIC}=4 \mu \mathrm{g} / \mathrm{mL}$ ). The presence of $\operatorname{lin} \mathrm{B}$ has also been described for a Streptococcus agalactiae isolate of human origin in Ontario, Canada (De Azavedo et al., 2001). Whether lateral gene transfer plays a role in interspecies dissemination of this resistance gene cannot be determined based on the data presented in our study, but the potential for such transfer has been suggested (De Azavedo et al., 2001). Based on current guidelines for interpretation of phenotypic assays, which do not include an intermediate category for pirlimycin, 2 of $4 \operatorname{lin} \mathrm{B}$ positive isolates would have been categorized as pirlimycin susceptible by the agar disc diffusion test. All linB-positive isolates had inhibition zones of $18 \mathrm{~mm}$ or less, whereas isolates that were both erm B- and lin B-negative had inhibition zones of $24 \mathrm{~mm}$ or greater. Recommended cutoff values for pirlimycin resistance or susceptibility may need to be reconsidered, preferably with inclusion of clinical data and larger and more geographically diverse collections of isolates than the isolates included in this study.

Spiramycin is not available on the US market, but is among the most commonly used macrolides for treatment of bovine mastitis and other production animal diseases in France. This study was initiated in part because results from antimicrobial resistance testing of mastitis pathogens in a veterinary practice suggested a high prevalence of spiramycin resistance among Strep. uberis isolates when recommended cutoff values for agar disc diffusion assays (Bryskier, 1999) were used for interpretation of test results. Of 55 isolates included in the current report, less than half $(\mathrm{n}=26$, or $47 \%)$ would be considered susceptible or intermediately resistant, but known resistance genes were detected only in less than a quarter $(\mathrm{n}=12$, or $22 \%)$ of isolates. The presence of resistance genes other than erm $\mathrm{B}$ or mef $\mathrm{A}$ cannot be ruled out, but we are not aware of any published reports on other macrolide resistance genes in Strep. uberis. Attempts to amplify a potential spiramycin-specific resistance gene, the methyl transferase gene srmA (Pernodet et al., 1999), were not successful (data not shown). Based on MIC testing, only 
erm B-positive isolates were classified as spiramycin resistant. The mechanisms behind the intermediate spiramycin susceptibility or spiramycin resistance observed for ermB-negative isolates by means of MIC or agar disc diffusion testing, respectively, and its clinical relevance in vivo, remain unresolved.

In conclusion, the agar disc diffusion method is a useful tool for identification of erythromycin and pirlimycin resistance in Strep. uberis isolates in veterinary practice. For reliable detection of pirlimycin resistance, the D-test needs to be performed. This is a simple modification of the agar disc diffusion method and can easily be implemented in practice. Isolates that are susceptible to erythromycin but resistant to pirlimycin are likely to harbor the $\operatorname{lin} \mathrm{B}$ gene. For detection of this type of resistance, the D-test is not needed, but resistance may go unnoticed if current guidelines for interpretation of inhibition zones are used. Isolates that show high-level resistance to spiramycin based on inhibition zones (no growth inhibition) or MIC values ( $\geq 8 \mu \mathrm{g} / \mathrm{mL}$ ) are likely to carry the erm $\mathrm{B}$ gene and show resistance to erythromycin. Isolates that show a lower level of resistance or intermediate susceptibility to spiramycin based on inhibition zones (12 to $16 \mathrm{~mm}$ ) and MIC values $(4 \mu \mathrm{g} / \mathrm{mL})$ but no resistance to erythromycin are relatively common ( 17 of 55 , or $31 \%$ of isolates in this study). Further work is needed to elucidate the underlying mechanism and the importance of this level of resistance for treatment response in vivo.

\section{ACKNOWLEDGMENTS}

The authors thank Martin Pol and Carol Hulland at the University of Wisconsin, Madison, and Merial, France, for MIC measurements. This project was supported in part by USDA Cooperative State Research, Education, and Extension Service award 2004-3520414220 to study the molecular epidemiology and transmission of Strep. uberis in dairy herds. We are grateful to Jeff Watts from Pfizer Animal Health (Kalamazoo, MI) for helpful suggestions on resistance testing.

\section{REFERENCES}

Altschul, S. F., T. L. Madden, A. A. Schaffer, J. Zhang, Z. Zhang, W. Miller, and D. J. Lipman. 1997. Gapped BLAST and PSI-BLAST: A new generation of protein database search programs. Nucleic Acids Res. 25:3389-3402.

Barkema, H. W., Y. H. Schukken, and R. N. Zadoks. 2006. Invited review: The role of cow, pathogen, and treatment regimen in the therapeutic success of bovine Staphylococcus aureus mastitis. J. Dairy Sci. 89:1877-1895.

Bozdogan, B., L. Berrezouga, M. S. Kuo, D. A. Yurek, K. A. Farley, B. J. Stockman, and R. Leclercq. 1999. A new resistance gene, lin $\mathrm{B}$, conferring resistance to lincosamides by nucleotidylation in Enterococcus faecium HM1025. Antimicrob. Agents Chemother. 43:925-929.
Bryskier, A. 1999. Antibiotiques, agents antibactériens et antifongiques. Ellipses Marketing, Paris, France.

CLSI. 2004. Performance Standards for Antimicrobial Disk and Dilution Susceptibility Tests for Bacteria Isolated from Animals. Approved Standard M31-A2. Second ed. Clinical Laboratory Standards Inst. (formerly NCCLS), Wayne, PA.

Constable, P. D., and D. E. Morin. 2003. Treatment of clinical mastitis. Using antimicrobial susceptibility profiles for treatment decisions. Vet. Clin. North Am. Food Anim. Pract. 19:139-155.

De Azavedo, J. C., M. McGavin, C. Duncan, D. E. Low, and A. McGeer. 2001. Prevalence and mechanisms of macrolide resistance in invasive and noninvasive group B streptococcus isolates from Ontario, Canada. Antimicrob. Agents Chemother. 45:3504-3508.

Deluyker, H. A., S. N. Van Oye, and J. F. Boucher. 2005. Factors affecting cure and somatic cell count after pirlimycin treatment of subclinical mastitis in lactating cows. J. Dairy Sci. 88:604-614.

Erskine, R. J., R. D. Walker, C. A. Bolin, P. C. Bartlett, and D. G. White. 2002. Trends in antibacterial susceptibility of mastitis pathogens during a seven-year period. J. Dairy Sci. 85:1111-1118.

Furrer, B., U. Candrian, C. Hoefelein, and J. Luethy. 1991. Detection and identification of Listeria monocytogenes in cooked sausage products and in milk by in vitro amplification of haemolysin gene fragments. J. Appl. Bacteriol. 70:372-379.

Grave, K., C. Greko, L. Nilsson, K. Odensvik, T. Mork, and M. Ronning. 1999. The usage of veterinary antibacterial drugs for mastitis in cattle in Norway and Sweden during 1990-1997. Prev. Vet. Med. 42:45-55.

Guérin-Faublée, V., F. Tardy, C. Bouveron, and G. Carret. 2002. Antimicrobial susceptibility of Streptococcus species isolated from clinical mastitis in dairy cows. Int. J. Antimicrob. Agents 19:219-226.

Hassan, A. A., I. U. Khan, A. Abdulmawjood, and C. Lämmler. 2001. Evaluation of PCR methods for rapid identification and differentiation of Streptococcus uberis and Streptococcus parauberis. J. Clin. Microbiol. 39:1618-1621.

Hoe, F. G., and P. L. Ruegg. 2005. Relationship between antimicrobial susceptibility of clinical mastitis pathogens and treatment outcome in cows. J. Am. Vet. Med. Assoc. 227:1461-1468.

Levin, T. P., B. Suh, P. Axelrod, A. L. Truant, and T. Fekete. 2005. Potential clindamycin resistance in clindamycin-susceptible, erythromycin-resistant Staphylococcus aureus: Report of a clinical failure. Antimicrob. Agents Chemother. 49:1222-1224.

Loch, I. M., K. Glenn, and R. N. Zadoks. 2005. Macrolide and lincosamide resistance genes of environmental streptococci from bovine milk. Vet. Microbiol. 111:133-138.

Martel, A., A. Decostere, E. D. Leener, M. Marien, E. D. Graef, M. Heyndrickx, H. Goossens, C. Lammens, L. A. Devriese, and F. Haesebrouck. 2005. Comparison and transferability of the erm (B) genes between human and farm animal streptococci. Microb. Drug Resist. 11:295-302.

McDougall, S., K. E. Agnew, R. Cursons, X. X. Hou, and C. R. Compton. 2007. Parenteral treatment of clinical mastitis with tylosin base or penethamate hydriodide in dairy cattle. J. Dairy Sci. 90:779-789.

Milne, M. H., A. M. Biggs, D. C. Barrett, F. J. Young, S. Doherty, G. T. Innocent, and J. L. Fitzpatrick. 2005. Treatment of persistent intramammary infections with Streptococcus uberis in dairy cows. Vet. Rec. 157:245-250.

National Mastitis Council. 1999. Laboratory Handbook on Bovine Mastitis. Natl. Mastitis Counc., Madison, WI.

Pernodet, J. L., A. Gourmelen, M. H. Blondelet-Rouault, and E. Cundliffe. 1999. Dispensable ribosomal resistance to spiramycin conferred by srmA in the spiramycin producer Streptomyces ambofaciens. Microbiol. 145:2355-2364.

Raymond, M. J., R. D. Wohrle, and D. R. Call. 2006. Assessment and promotion of judicious antibiotic use on dairy farms in Washington State. J. Dairy Sci. 89:3228-3240.

Roberts, M. C. 2002. Resistance to tetracycline, macrolide-lincosamide-streptogramin, trimethoprim, and sulfonamide drug classes. Mol. Biotechnol. 20:261-283. 
Sawant, A. A., L. M. Sordillo, and B. M. Jayarao. 2005. A survey on antibiotic usage in dairy herds in Pennsylvania. J. Dairy Sci. 88:2991-2999.

Sutcliffe, J., T. Grebe, A. Tait-Kamradt, and L. Wondrack. 1996. Detection of erythromycin-resistant determinants by PCR. Antimicrob. Agents Chemother. 40:2562-2566.

Tenhagen, B. A., G. Koster, J. Wallmann, and W. Heuwieser. 2006. Prevalence of mastitis pathogens and their resistance against antimicrobial agents in dairy cows in Brandenburg, Germany. J. Dairy Sci. 89:2542-2551.

Wondrack, L., M. Massa, B. V. Yang, and J. Sutcliffe. 1996. Clinical strain of Staphylococcus aureus inactivates and causes efflux of macrolides. Antimicrob. Agents Chemother. 40:992-998.

Zwald, A. G., P. L. Ruegg, J. B. Kaneene, L. D. Warnick, S. J. Wells, C. Fossler, and L. W. Halbert. 2004. Management practices and reported antimicrobial usage on conventional and organic dairy farms. J. Dairy Sci. 87:191-201. 